\title{
Corporalidades y sexualidades no normativas en el tango prostibulario
}

\section{Non-normativa corporalities and sexualities in brothel tango}

Sofía Cecconi*

\section{Resumen}

Este trabajo analiza el período en el que el tango fue considerado música prohibida -entre fines del siglo XIX y principios del siglo XX-, etapa interesante porque el tango fue, sin proponérselo, la expresión de una sociedad que atravesaba un momento de fundación, en un clima de conflicto social y "desorden" moral, sexual y de género. En ese entonces el tango congregaba a su alrededor a seres marginales, en virtud del sitio del cual emergió: el prostíbulo. Podría decirse que su discurso -música, letrillas y danza- ponía en contacto de una manera inquietante a quienes expresaban formas de la subjetividad alternativas a las dominantes con quienes se suponía que encarnaban la normalidad. El artículo aborda la conformación de esas corporalidades no normativas vinculadas a las figuras del tango, atendiendo también a los intentos que se desplegaron para controlar el flujo de su diferencia.

Palabras clave: tango, género, sexualidad, cuerpo, siglo XIX, Buenos Aires

\begin{abstract}
This article analyzes the period in which tango was considered forbidden music -between the end of the 19th century and the beginning of the 20th century-, a period in which tango was, without trying to, the cultural expression of a society mobilized by a climate of social conflict and moral, sexual and gender "disorder". At that time, tango congregated marginal people around it, because of the place it emerged: the brothel. In this sense, its discourse -music, lyrics and dance- brought together those who expressed alternative forms of subjectivity, with those who were supposed to embody normality. The article examines the conformation of these non-normative corporality related to the tango figures, taking into account the attempts deployed to control the flow of their difference.
\end{abstract}

Keywords: Tango, Gender, Sexuality, Body, 19th Century, Buenos Aires

Fecha de recepción: Noviembre 2020

Fecha de aprobación: Junio 2021

\footnotetext{
* Socióloga y doctora en Ciencias Sociales por la Facultad de Ciencias Sociales de la Universidad de Buenos Aires, Argentina. Es docente de esa misma casa de estudios y también de la UNDAV, Argentina. Realizó estudios de posgrado en la Freie Universität zu Berlin. Ha publicado artículos referidos al tango, la cultura, cuestiones de género y jóvenes en libros y revistas especializadas.
} 


\section{Introducción \\ El tango y los cuerpos que (no) importan: la prostituta y el compadrito"}

El tango y el prostíbulo configuraron un espacio real y simbólico de pertenencia para esos seres perseguidos. El prostíbulo, como el conventillo, constituyó un lugar fuertemente cargado de simbolismo, donde se daban cita las transgresiones, el libertinaje y la algarabía que desafiaba la seriedad del orden.

Distintos autores coinciden en que los prostíbulos eran ámbitos que invitaban a la mezcla: allí se cruzaban la prostituta, el "niño bien" -el hijo de la oligarquía-, el trabajador, el miembro de la élite, el travesti y el homosexual, situación que despertaba gran inquietud entre los sectores dirigentes, pues se producía una convivencia temporal de categorías que se concebían como irreconciliables entre sí. Especial preocupación causaban las visitas en patota de los "niños bien" y los disturbios que provocaban. Al respecto, Tallón ${ }^{1}$ señala la zozobra de las familias de la clase alta por "el desorden moral en que vivieron los suburbios -y también una parte de la juventud de las clases más altas-" (1964, p. 5). Los periódicos se hacían eco de esta preocupación:

“En 1896 el diario La Nación comenta una riña sangrienta que se produjo en el teatro El Pasatiempo - un baile de delincuentes-, y al describir el ambiente y los protagonistas, se refiere a los varones en estos términos: «Los concurrentes masculinos, jóvenes casi todos, hombres de bronce y casi niños de buena familia con aspectos de colegiales»" (citado por Vega, 2007, p. 121 122).

Pero debe señalarse que, junto con la desconfianza "desde arriba", el tango y sus personajes también recibían miradas críticas "desde abajo". Según Tallón, los inmigrantes "honestos y trabajadores" observaban con recelo a esos grupos:

"Las familias proletarias decentes sufrían en silencio o no se escandalizaban demasiado, por fuerza de la costumbre -en los conventillos, en los inquilinatos, en la vecindad-de vivir en su medio en promiscuidad con toda clase de delincuentes. (...) Dominaban con la prepotencia y el terror al suburbio entero los peligrosos." (Tallón, 1964, p. 4).

Aunque no todos en el arrabal respondían a la "mala vida", su cultura impregnaba la cotidianeidad de los sectores populares. Esta presencia inquietante también resultaba amenazadora para las capas medias. Como señala el mismo autor,

"Lo que odiaban y temían las familias obreras y las de los barrios centrales de la clase media, era la disolución moral que encarnaba el

\footnotetext{
1 El texto de José Sebastián Tallón, "El tango en sus etapas de música prohibida", publicado postmortem, se basa, según se señala en el prólogo, en un "riguroso bagaje documental" apoyado en la consulta de viejos diarios y revistas, en el relato de algunos "veteranos" que habían vivido esa época en primera persona y, fundamentalmente, en su experiencia directa -sus "recuerdos de vecino de Barracas y San Telmo"-. Por ello, es una fuente privilegiada para aquellos que se dedican al estudio de aquel período del tango.
} 
Revista Punto Género N.15 Junio de 2021

ISSN 0719-0417 / 137- 154

compadre. La coreografía nocturna de los burdeles distaba mil leguas de quedarse en sí misma, como arte puro; y sobre ello, las intimidades del orbe perverso y de los que en él se revolcaban no eran un secreto para nadie. En que no fuesen un secreto estaba, precisamente, lo horrible. En los hijos que volvían al amanecer y después se los sentía cargados de experiencias impúdicas, y muy envanecidos con ellas, la familia veía sin equivocarse las avanzadas de una invasión." (Tallón, 1964, p.11).

Como señala Matamoro (1969, p. 54), en la orilla convivían los sectores populares y los marginales, se confundían, se solapaban. Las contradicciones asociadas con esta situación de mezcla, que fuera del prostíbulo se manifestaban con la tensión propia de un malestar social, encontraban en él un ámbito donde lo contradictorio podía convivir y desplegarse.

En ese contexto liminar, las prostitutas constituían uno de los cuerpos abyectos centrales: así las definían médicos, criminólogos, escritores, higienistas y ensayistas, que consideraban la prostitución como un problema social de envergadura. La posición de las prostitutas era de subordinación y sumisión respecto al poder masculino y, en su relación con otras mujeres, permanecían también en los bordes: eran todo aquello que "una mujer" no debía ser: libertinas, sexualizadas, erotizadas, sensuales, fuertes2. Nada más alejado de la mujer casta, sacrificada, doméstica que establecía la representación dominante tanto en las clases altas como bajas. Cuerpo abyecto el de la prostituta, porque su hábitat natural era el prostíbulo, la orilla. Fuera de sus muros protectores, cuando salía de "levante", taconeando las calles en busca de clientes, se convertía en centro de miradas que censuraban sus ropas y modales, considerados tan inadecuados para una mujer decente como propios de un cuerpo entregado al sexo pago.

Las "madamas" -las mujeres que regenteaban los prostíbulos- poseían, además, otra peculiaridad que reforzaba la oblicuidad de su condición, relacionada con su vínculo con el rufián, donde los roles tradicionales de género se veían parcialmente trastocados. Uno de los pocos registros existentes acerca de esto es el relato de tintes antropológicos que escribió Tallón (1964), mencionado anteriormente. En el apartado "Intimidad de «El Cívico» y «La Moreira»" describe la relación entre la madama -hija de andaluces gitanosy su pareja -un proxeneta-, quienes compartían una pieza en el conventillo El Sarandí. Tallón señala que El Cívico se dedicaba a "la explotación de su mujer, "La Moreira", y (a) la pesca y tráfico comercial, al contado, de pupilas nuevas". Y que La Moreira

"«trabajaba» como pupila, como lancera, como proxeneta y como bailarina. Como lancera, porque tiraba la lanza (la punga) a los giles3 alcoholizados y al gringuerío con plata; como proxeneta, porque era socia de

\footnotetext{
2 Soler Cañas (1965: 31) muestra cómo se describían estos personajes en la literatura popular de la época.

3 En el Río de la Plata, aun hoy, se utiliza el término "gil" para aludir a una persona tonta, cándida e ingenua (Cfr. Conde, 2004: 172). Usualmente el "gil" es fácil de engañar; puede tratarse de una persona honesta que, en un ambiente marginal, puede ser fácilmente estafada por quienes viven del delito.
} 
su «marido» en eso de engatusar infelices y de venderlas como «novedades»; como bailarina, porque lo fue en grado sumo, y porque en el café de La Pichona fue uno de los que ayudaron a darle al tango la fama de prostibulario que se le asigna. Ella era en la noche una mujer del tango. En las venas le murmujeaba la bravura gitana, $y$, con ser tan femenina en su apariencia, $y$ tan hermosa, en sus tareas sombrías era de mucho "valor» como tiradora de daga, y de ahí su apelativo. Comúnmente usaba un puñal; pero, cuando debía aventurarse sola en las noches de más afuera o en los «negocios» difíciles basta pensar en el resentimiento de los rufianes de menor cuantía, flojones, maulas, pero no por ello menos peligrosos, a los que ella quitaba sus mujeres-, salía con botas de caña alta, que llegaban casi a la rodilla, y en la derecha calzaba la daga o un sable bayoneta. No se olvide, los suburbios vivían una época de lujuria y violencia demenciales. Su figura: no muy alta, de formas perfectas, la voz sensual, como su rostro; como su andar." (Tallón, 1964, p. 6-8).

Más adelante, el autor señala la peculiar relación que mantenía con su pareja:

"Cuando [El Cívico] le pegaba, ella se dejaba pegar, siendo, como era, capaz de pelearlo como un guapo, porque no la castigaba con la brutalidad de los que no tenían recursos mejores para señorear a sus rameras, sino con exigencias de dueño lindo, o de enamorado celoso" (Tallón, 1964, p. 11).

En esta descripción se observa el tipo de relación que tenían la "madama" y el "cafishio"4. En principio, el proxeneta explota a su mujer, ejerciendo una fuerte dominación sobre ella. Sin embargo, también señala que son "socios", con lo cual, aparece una relación de paridad que pone en suspenso la tradicional relación de subordinación: ella selecciona a las pupilas y enfrenta a otros rufianes, en una acción temeraria, poco esperable de una mujer para la época. Así, la figura de El Cívico pierde fuerza ante una compañera posicionada como proveedora y ocupando el polo activo de la relación: ella trabaja, es regente de sus "pupilas" y la que obtiene ingresos para comprarle al rufián todo lo requiere, como veremos enseguida.

La tradicional relación de género entre varón y mujer, donde el varón provee económicamente para que la mujer vista elegante y al mostrarse así reafirme la virilidad de un compañero que la exhibe como objeto, está aquí tergiversada. Se trata, además, de una mujer a todas luces "masculinizada", portadora de rasgos que escapan a la representación sumisa y pasiva de la mujer: irrumpe en la escena con seguridad y arrojo ("tiraba la lanza a giles", poseía "bravura", "era de mucho valor", "se aventuraba sola por las noches") y su atuendo se aleja de los vestidos que la época consideraba apropiados para las mujeres: botas de caña alta, pañuelo al cuello, ropa de fajina y camisa de hombre. Como si esto fuera poco, porta un puñal, arma fálica propia del compadre, y su actitud belicosa termina por confirmar su posición de sujeto, por si alguna duda quedara.

\footnotetext{
${ }^{4}$ En el lenguaje lunfardo del Río de la Plata de la época, se denominaba "cafishio" a los rufianes y/o proxenetas (Cfr. Conde, 2004, p. 79).
} 
Junto con estas características que demuestran el escaso apego de la madama hacia los patrones normativos de género, hay otros aspectos que responden a esas pautas tradicionales: se la describe como una mujer hermosa, "femenina en apariencia" y sensual, que, a pesar de poder enfrentar al rufián, se sometía voluntariamente a su brutalidad, interpretada como demostración amorosa. Aunque esta mujer acepta esa violencia, no lo hace desde el sacrificio y la abnegación -como sucede típicamente en las mujeres eficazmente interpeladas por la norma tradicional- sino desde una naturalidad distinta, propia de la vida de los márgenes, la naturalidad de la violencia que rige la ley del fandango y la parranda prostibularia en la que vive. En muchos sentidos, La Moreira es una mujer masculina, que no calla, que arremete, que se jacta de sus destrezas sexuales, de su bravura, valor y "aguante". Por eso, a su sexo biológico de mujer y la orientación de su deseo hacia el rufián no le corresponde un género netamente "femenino". Como hemos visto, su vestimenta es más bien masculina, como también sus modales, su gestualidad y su posición como sujeto proveedor. Por ello, más que adscribir a una categoría normativa (mujer/femenina) circula por ellas (mujer/masculinizada), mezclando sus contenidos, rompiendo en definitiva con lo que Butler denomina el orden obligatorio sexo/género/deseo ${ }^{5}$.

Siguiendo el planteo de Butler, el género es un hacer: ni sustantivo ni atributo, se constituye a partir de un acto performativo que deviene de una "práctica reiterativa y referencial mediante la cual el discurso produce los efectos que nombra" (Butler, 2001). La performatividad, diría Butler, consiste en una apelación a la cita ineludible a través de la cual se reproduce el régimen de heterosexualidad obligatorio. Pero esta práctica reiterada y regulada nunca logra establecerse plenamente. Desde esta perspectiva, es claro que la madama con su performance masculinizada ponía en evidencia la arbitrariedad de la norma que obliga a las mujeres a vestir, actuar y sentir de una manera determinada, "femenina", una norma que ella no siempre citaba. Al contrario, su cita hacía hiperbólica la norma que regula la presentación ante los demás de ciertos atributos masculinos, con lo cual evidenciaba la arbitrariedad del orden que establece una contigüidad entre ciertas formas del sexo, el género y el deseo. Con su performance masculinizada, La Moreira mostraba que lo que una mujer "es" no puede ser completamente contenido ni controlado por la matriz cultural dominante: su performance está sobredeterminada por la posición que ocupa en relación con el cafishio, con sus clientes y con las otras mujeres para las cuales conforma su "exterior constitutivo" -o uno de los exteriores del universo de lo abyecto-.

No puede soslayarse que la presentación masculinizada de La Moreira y otras

\footnotetext{
${ }^{5}$ Butler sostiene que el orden obligatorio de sexo/género/deseo establece una linealidad entre esas tres categorías, fundada en un pensamiento binario según el cual a los "dos" sexos corresponden dos géneros y dos orientaciones del deseo y las prácticas sexuales. De acuerdo con ello, el orden obligatorio regula una correspondencia entre el sexo masculino, la identidad de género masculina y la orientación del deseo hacia las mujeres, para los varones e inversamente para las mujeres. Así, la matriz cultural excluye ciertas identidades del campo de lo inteligible, por tratarse de identidades en las que el género no es consecuencia del sexo o en las que el deseo y las prácticas sexuales no se derivan ni del sexo ni del género, interpretándolas como el producto de un desarrollo fallido.
} 
prostitutas activara la sospecha de ciertos sectores. Porque en una sociedad con alta tasa de masculinidad, que concebía como legítimo el placer masculino -no el femeninoasociado a las prácticas heterosexuales, la prostitución femenina era tolerada como un mal menor. Pero qué pensar de estas mujeres que parecían -o simulaban ser- varones en su aspecto, de estas "marimachos" como La Moreira u otras como María La Vasca, Rosita Quiroga, Pepita Avellaneda, Paquita Bernardo, todas mujeres vinculadas al tango, cuya performance era masculinizada ¿no sería acaso que su modo de vestir comunicara otra cosa?

El cuestionamiento de la moral burguesa que se daba en el prostíbulo no terminaba allí. En el lupanar nada era nítido, categórico ni estable. A las mujeres que parecían varones se sumaban los varones que parecían mujeres. Un caso prototípico es el compañero de La Moreira, El Cívico del relato de Tallón, otro cuerpo "abyecto". Además de vivir de las mujeres, y con ello demostrar su despreocupación frente a los roles asociados normativamente a su condición de varón, vestía de manera más que sugestiva. En ese relato se lo describe como un ser que se mantenía "lindo" gracias a los cuidados que la madama le dispensaba, siempre arreglado, vestido con camisas de primera, sacos floreados, trencillas, e incluso maquillado. Tallón también enumera minuciosamente todos los elementos de aseo, cuidado personal y maquillaje que El Cívico tenía en su baño y agrega al respecto:

"para vestirse y adornarse los compadritos eran exagerados. Eran exagerados en todo. El término relajados era el que se usaba para definirlos en la época. A los que llegaban a los extremos tales como ponerse anillos sobre los guantes, los llamaban relajados los compadritos mismos. Imitaron la moda de los ricos, y se trajearon y acicalaron con un narcisismo exagerado de mujer, evidentemente sexual y sospechoso; tomaron el tango y lo llevaron a los medios sexuales obscenos. El contoneo criollo del caminar, que tuvo su origen en los tacos altos, ellos lo hicieron medio tilingo si no amariconado. $Y$ de la misma manera, a la coreografía del tango le dieron un estilo propio de exageraciones eróticas" (Tallón, 1964, p. 10).

En consonancia, el subcomisario Batiz describe a estos personajes del siguiente modo: "exagera las modas en el vestir, usa botines de tacón alto y fino, sombrero chambergo, corbata de colores llamativos, es el sujeto orillero" (Batiz, 1908, p. 43). Relajado, amariconado, coqueto, acicalado, narcisista, sensual, tilingo ${ }^{6}$, erótico, imitador, todas cualidades reunidas en el cuerpo del compadrito, quien por todo ello se convertía, a los ojos normativos de la oligarquía local, en centro de sospechas. En primer lugar, sospechoso por imitar a las mujeres en la preocupación que evidenciaba por el cuidado de su aspecto. En segundo, por simular una clase a la que no pertenecía: la estrategia de imitar la moda de los ricos para asimilarse y confundirse con ellos, causaba repulsión en las clases altas y fue contrarrestada con el "titeo" (Salessi, 2000, p. 141).

El compadrito constituía un ser ambiguo, exagerado, dudoso. Por un lado, al igual

6 El término rioplatense "tilingo" solía utilizarse para aludir a una persona vulgar, superficial, jactanciosa, presumida, que se comporta con afectación (Cfr. Conde, 2004: 300-301) 
que su compañera, ponía en crisis la binariedad y estabilidad del orden obligatorio, al desplazarse a través de categorías pensadas como cerradas y estancas: su sexo biológico masculino no se continuaba claramente en una performance de género masculina, ni tampoco en una nítida orientación del deseo, que por el contrario resultaba tan ambigua como su vestimenta. Por otro lado, su posición generaba malestar porque, al imitar a los ricos, jugaba con las jerarquías sociales, mostrando con su actuación que en una sociedad plebeya y aluvional como la Buenos Aires de fin de siglo, cualquiera podía confundirse con quienes estaban ubicados en las posiciones más altas. Además, Tallón (1964, p. 17) observa: "Por la pinta y modales se les querían parecer los muchachos «sin antecedentes» del pueblo y del bajo pueblo". Es decir que el compadrito también era peligroso porque los jóvenes trabajadores querían imitarlo: participaban de una cultura popular, donde lo percibido como disvalor desde arriba, generaba admiración desde abajo.

\section{El baile y las letrillas en el tango prostibulario}

Putas, compadritos, homosexuales, maricas, todos ellos formaban parte del mundo del tango, de sus noches de fiesta, violencia y baile. Así lo recordaba Tallón en el texto citado: "Si no había trifulcas y detenciones, hasta el amanecer no se daban tregua los musiqueros. Y los homosexuales, y las escenas droláticas y grotescas" (1964, p. 12). Escenas de despilfarro y bajofondo, de diversión y desenfado, de excesos y violencia. Este mundo marginal, como señalamos, ocupaba un lugar ambiguo: socialmente rechazado por las clases medias y bajas, pero frecuentado por sus jóvenes; lugar de perdición para las mujeres de clases humildes, pero una de sus escasas fuentes de ingresos. Un espacio de rejuntes, de paradojas, de contradicciones tan intensas como reales, que acaso hayan sido el motor que puso en marcha el tango, su baile y sus primeras letrillas.

La noche tanguera, con sus personajes marginales y sus excesos, también se expresaba en letrillas que celebraban diversas formas del goce corporal, al tiempo que se enunciaba con el cuerpo mediante esa forma erotizada de la danza que es el tango llamado originario ${ }^{7}$. Si el prostíbulo y los cuerpos que lo frecuentaban eran repudiados por las clases acomodadas, también las formas del baile, la música y las letrillas, emergentes del tango en ese espacio, eran rechazadas por la oligarquía y las clases medias, por considerarlos una propuesta impúdica e indecorosa. Esta situación lleva a Tallón a definir esta fase como "etapa prohibida" del tango.

La alarma y el rechazo que despertaba este baile puede rastrearse en numerosos discursos. Uno de los portavoces de las clases altas, Leopoldo Lugones, afirmaba en una columna del diario La Nación de 1913:

\footnotetext{
7 Existen numerosas dificultades para dar cuenta de estas dimensiones del tango (sus letras y las forms de su danza) en el período abordado: la condición oral de esta cultura, su carácter espontáneo y no oficial, en muy pocos casos ha dejado testimonio escrito. Además, la dimensión performática del baile carece, en virtud de la época, de registros fílmicos. Por ello, las fuentes utilizadas suelen ser indirectas: crónicas periodísticas, escritos médicos y, policiales, literatura de la época y poesía lunfarda.
} 
"el objeto del tango es describir la obscenidad. (...) resume la coreografía del burdel, siendo su objeto fundamental el espectáculo pornográfico" (en Lamas y Binda, 2008: 194). Ese año, el mismo periódico publicó una editorial: "El tango es una danza del suburbio, lúbrica y grosera. Carece de gracia, de amplitud y de nobleza. (...) El tango corresponde entre nosotros a una clase inferior y a un momento de transición promiscua. No hay más que observar los movimientos sensuales y sus cadencias guarangas, para comprender que provienen de extramuros (...) repudiar esa danza bastarda, que se condecora insolentemente con el título de "argentina" y que pretende expresar con sus gestos de burda lujuria los sentimientos estéticos de todo un pueblo" (en Binda y Lamas, 2008, p. 268-269).

En 1906, el escritor Juan Pablo Echagüe también lo describía con desdén:

"Bailar tango es hoy ejecutar dificultosas contorsiones y piruetas. Primero se le tomaron los zapateos al gato, los tropes al pericón, las carreras laterales a la polca, los cortos pasitos de la mazurca; promiscuáronse los diversos meneos y se obtuvo una estrafalaria variedad de cabriolas que las parejas combinan a su antojo en un solo compás" (en Vega, 2007, p.132).

Desde otra perspectiva, el baile denunciado puede ser interpretado como una forma de contradiscursividad que aborda escénicamente la temática de la sexualidad de un modo alternativo, preconizando la mezcla erotizada y festiva de cuerpos. Tallón habla del tango como coreografía orillera: "Cortes y quebradas, lujurias, vocería guaranga, botellas, manoseos torpes, dagas celosas, humo." (1957, p. 17), describiendo a la vez el ambiente donde se desarrollaba el baile y dos de sus pasos más característicos: el corte y la quebrada, como si esos pasos expresaran ese clima espeso, violento y sexualizado, de manoseos, dagas, humo y lujuria.

Es interesante detenerse en el modo en que estos observadores se refieren al tango. Menearse, hacer piruetas y acrobacias carentes de nobleza, movimientos guarangos, pornográficos, estrafalarios y antojados, improvisados, espontáneos podríamos agregar. El campo semántico que construyen, por un lado, enfatiza la hibridación de la cual el baile es resultado: la mezcla aparece así nuevamente como un aspecto recurrente e intolerable. Por otro, se lo califica como movimiento ordinario, falto de "clase", "promiscuo", expresando con contundencia el rechazo que provoca esa sexualidad exacerbada atribuida al baile ${ }^{8}$.

El estilo de baile de esta época, conocido como "canyengue" u "orillero", reposaba fundamentalmente en la improvisación de los bailarines. Esta característica puede sumarse a la supuesta lujuria del baile como posible motivo de rechazo: el tipo de figuras que se realizaban durante la improvisación y el espíritu lúdico y flexible que las animaba, se contraponía claramente a las formas cerradas, decorosas y previsibles de las danzas

\footnotetext{
${ }^{8}$ Esta cualidad híbrida de la que es producto la coreografía del tango es algo que también señaló Savigliano, haciendo énfasis en otras dimensiones: "La coreografía del tango emerge de la admiración mutua y el desdén malicioso entre las diferentes razas, clases y etnias, lumpenizadas todas en la ciudad." (1995: 31. Traducción propia).
} 
"decentes" de la burguesía. Por eso, el observador citado denuncia, además de la mezcla sexualizada de esos movimientos, la arbitrariedad que rige su combinación ("al antojo" de la pareja de baile), como si esa carencia de una coreografía preestablecida, esa aparente ausencia de norma y regularidad, connotara, a su vez, el fuera de la norma del baile y sus protagonistas.

Para reconstruir las performances de estas parejas también podemos recurrir a la descripción que realiza Carloen su escrito Nuestra América de 1905:

"De esos bailes, hoy injertos en meneos andaluces, ha sacado la plebe gauchesca lo que llama bailar con corte, con puro corte a la quebrada, es decir quebrando y balanceando, acompasadamente, el cuerpo en un completo contacto de ambos bailarines, entre cuyas personas tan íntimo es ese contacto que no siempre -según la expresión popular- hay luz" (en De Lara et al, 1981, p. 264).

Unos años más tarde, en 1910, Marcelino del Mazo publica unos versos donde se describe esta danza emergente en un sentido semejante:

"Cuando el ritmo de aquel tango les marcó un compás de espera

como sierpes animadas por un vaho de pasión,

se anudaron... y eran gajos de una extraña enredadera

florecida entre las lluvias de los dichos del salón

¡Aún m’hija! -aulló el compadre- y la fosca compañera

ofreció la desvergüenza de su cálido impudor,

azotando con su carne como lengua en una hoguera,

las vibrátiles entrañas de aquel chusma del amor."

(en De Lara et al, 1981, p.270).

Se habla en estos versos de serpientes -los reptiles del pecado original-, de pasión, de desvergüenza, de impudor, de lenguas, de hoguera, de carne, todos significantes que reenvían directamente al terreno de la sexualidad, elementos característicos de la discursividad de la época para describir el baile. Ellos también brindan claras pistas sobre los movimientos típicos del tango prostibulario: se habla de cuerpos que se anudan, de esperas o cortes, de vibraciones, de balanceos acompasados, de quiebres y contactos.

Vicente Rossi fue uno de los primeros en analizar el baile del tango en un escrito publicado en 1926, donde compara la forma que adquiere en Buenos Aires, de la mano de los compadritos, con aquella que considera originaria, propia de los negros de Montevideo:

"El pardo y el blanco no se adaptaron a la técnica del negro, no tenían temperamento para ella. (...) Iba [el orillero] con ellas en un floreo de deslizamientos, interrumpidos de trecho en trecho por imprevistos croquis 
geométricos delineados sobre el suelo con los pies. (...) El orillero aprovechaba las situaciones de sensualizar" (Rossi, 2001, p. 142-143).

Aquí aparecen claramente el corte (las interrupciones) y la intención sensual que motoriza los movimientos de la pareja abrazada, como propios del baile del compadrito. La letrilla del tango Cuerpo de alambre, escrito en 1910 por el músico y poeta Ángel Villoldo, también se refiere a este baile, sumando otros pasos:

"Es mi china la más pierna

pa'l tango criollo con corte;

su cadera es un resorte

y cuando baila un motor.

Hay que verla cuando marca

el cuatro o la media luna,

con qué lujo lo hace jahijuna!...

Es una hembra mi flor."

(en Soler Cañas, 1965, p. 171).

Estos ejemplos brindan elementos que nos permiten reconstruir imaginariamente la primera coreografía del tango y comprender los estrechos lazos que lo unían al terreno de la sexualidad. Algo similar puede plantearse respecto de sus letrillas. Como vimos en apartados anteriores, la sexualidad fue un tema central en la época, abordado "desde arriba" por los tratados de higienistas y criminólogos. Pero esta cuestión circulaba también por lo bajo como un contradiscurso, articulado precariamente en letrillas de tango que expresaban una moral distante de la de médicos y juristas. En efecto, en este momento histórico, el tango no poseía letras en sentido estricto -sólo unas pocas llegaron a nuestros días- sino más bien letrillas tarareadas por los clientes en la antesala del burdel, que cambiaban cada vez manteniendo la misma melodía. Algunas de ellas, especialmente las escritas por Villoldo, llegaron luego a convertirse en letras en sentido estricto pero, al hacerse masivas, fueron modificadas, en un procedimiento que eliminó sus rasgos sexualizados y adecentó su contenido obsceno. Pero antes de que esto sucediera, ellas expresaban cabalmente el espíritu que animaba la noche prostibularia, con su contenido picaresco, en algunos casos hasta pornográfico. En su sentido sexualizado, cómico y exagerado también es fácil leer los rastros de una cultura popular que fue luego silenciada, una cultura que se asemeja a la descrita por Bajtin (1989) y que se distinguía por su carácter alegre, por su capacidad para albergar lo contradictorio sin dificultades, por su festiva celebración de la abundancia -del sexo en este caso-, por su tono picaresco y burlón de la seriedad que rige la vida ordinaria.

Estas letrillas y sus evocadores títulos pueden analizarse bajo esta luz, considerándolos como un discurso alternativo que expresa un modo muy diferente de vivir la sexualidad. Así, algunos de los títulos de estos primeros tangos hacen explícita referencia a los órganos genitales masculinos y femeninos, entre ellos El choclo, El 
serrucho, La budinera, Pan dulce. Otros, como El Queco son sinónimo del lugar del tango y la sexualidad -el burdel y su danza- o de su dinámica, como Dame la lata, título que evoca la mecánica del prostíbulo, donde el cliente recibía una latita como prueba del pago que debía entregar a la prostituta cuando era atendido (Matamoro, 1969; Salas, 1986). Estos y otros títulos son mencionados por Tallón (1964), quien agrega que se cantaba a la reina del prostíbulo en tangos como la Taquerita y otros que celebran el acto sexual y los juegos eróticos o la erección, como Afeitate el 7 que el 8 es fiesta, ¡Al palo!, Con qué trompieza que no dentra, Date vuelta, De quién es eso, Dejalo morir adentro, Dos sin sacar, El 69, El fierrazo, Empujá que se va a abrir, La concha de la lora, Metele bomba al Primus, Papas calientes, Qué polvo con tanto viento, Cara Sucia, Sacudime la persiana, Se te paró el motor, Hacéle el rulo a la vieja, Tocalo más fuerte, Tocalo que me gusta, Tocame la carolina, Tomame el pulso, Va Celina en la punta, Viejo encendé el calentador, - Bartolo toca la flauta popularizado como Andate a la Recoleta expresión que significaba "andate de juerga".

Más allá de la enumeración de estos títulos que resultan por demás elocuentes de los posibles contenidos de sus letras, el poeta y ensayista Salas (1986), sobreponiéndose a la dificultad existente para dar cuenta de las letras en este período, recopila los siguientes fragmentos del tango Bartolo, de indiscutible contenido prostibulario, cuya letra comienza:

“Bartolo tenía una flauta

con un agujerito solo.

Y la madre le decía:

Tocá la flauta Bartolo." (Salas, 1986, p. 56).

0

"Por coger con una mina

que era muy dicharachera

me han quedado los cojones

como flor de regadera" (Salas, 1986, p.60).

También cita esta otra:

"Con tus malas purgaciones

me llenaste un barril

y me tuviste en la cama

febrero, marzo y abril" (Salas, 1986, p. 60).

Soler Cañas cita los versos recogidos por el cronista Paggio hacia 1887:

"Estése quietito 
Revista Punto Género N․ 15 Junio de 2021

ISSN 0719-0417 / 137- 154

sosiéguese

No sea cargoso, caramba,

cómo es usted... "(Soler Cañas 1965, p. 47).

También puede mencionarse una letrilla anónima recogida por los hermanos Bates y Chicano:

"Chacarera chacarera/

chacarera de mi amor/

si yo te pido una cosal

no me contestes que no/

(...)

no me hagas sufrir/

todos duermen en tu camal

yo también quiere dormir/

(...)

La chacarera tiene una cosa/

que ella la guarda/

con gran cuidado/

porque es chiquital

y es muy sabrosa" (en Matamoro, 1969, p.59).

El contenido sexual de estas letras es evidente: la flauta de Bartolo es una alusión directa al pene; "coger" es un término que aún hoy se usa en Buenos Aires para referirse, de manera vulgar, a mantener relaciones sexuales; "cojones como regaderas" alude a una práctica sexual intensa. El sentido de otras letras se orienta en la misma dirección, apoyándose todas en una estética del exceso, de la exageración, de la sexualidad exacerbada, dimensión clave en todos los aspectos cuestionados del tango.

Del mismo modo, en los sainetes de la época se reponían algunos de los temas del tango que poco a poco comenzaban a salir del prostíbulo. Así, el comediante Roberto Gayol pone en boca de un rufián desairado por una mujer que eligió otro compañero de baile, el siguiente parlamento: “isi yo gozo cuando ligo/en las broncas por detrás!” (en Soler Cañas, 1965, p. 178), versos en los que Matamoro (1969.p. 51) reconoce un matiz homoerótico que condice con la caracterización que hiciéramos del compadrito en páginas anteriores. Esta versión del rufián pocas veces ha sido insinuada de manera tan abierta y resulta muy sugerente para abonar la hipótesis de que las formas de la sexualidad que se desplegaban en las letrillas que circulaban en el tango prostibulario respondían a un abanico mucho más amplio que el reconocido como válido por el régimen 
de heterosexualidad obligatorio.

Algo semejante puede plantearse respecto de la sexualidad femenina. Guy señala que estas primeras letras de tango "compartían una preocupación común respecto del género: los hombres dudaban de su capacidad para controlar a sus prometidas o a los miembros femeninos de sus familias". Y pone como ejemplo "Señor Comisario", cuya primera versión data de 1880 "Señor Comisario, déme otro marido, porque este que tengo no duerme conmigo. /Señor Comisario, yo he sido testigo, cuando la canalla cochina engañó al marido" (en Guy, 1994, p.178). Aquí se pone en cuestión la autoridad masculina sobre la mujer en el terreno de la sexualidad: es una mujer activa y demandante que recrimina y engaña a su compañero. Aun cuando en este caso el planteo se realiza en términos heterosexuales, es claro que se manifiesta bajo una forma diferente de la dominante, lejos de la construcción de género tradicional de la mujer subordinada, sumisa, pasiva y receptiva. Las cualidades atribuidas a la mujer son para la época claramente masculinas: deseante, activa, sexualmente desafiante.

Esta no adecuación a los roles de género pretendidamente naturales por los discursos médicos y criminológicos -mujer-pasiva-receptiva; varón-activo-proveedor-, expresada como una hipertrofia de la sexualidad, fuerza los límites de lo moralmente aceptable. Si bien los títulos y las letras reseñadas apuntan, por lo general, a temas hipersexualizados en términos masculinos y heterosexuales, no por ello dejan de ser disruptivos, en tanto que su estética del exceso y la visibilidad que pregonan de temáticas que deben acallarse, los coloca en un lugar poco aceptable para la moral burguesa de la época. Ese exceso, junto con la insinuación de formas anales de la sexualidad y a la posición activa de la mujer en ese terreno, son elocuentes de una matriz que no se ajusta plenamente al esquema binario y heterosexual postulado como natural.

Si el discurso médico y criminológico bregaba por una sexualidad normalizada, se expresa en estos textos una sexualidad festiva, no normativa, exagerada, hipertrofiada. Los cuerpos sexualizados que bailaban, actuaban y cantaban el tango constituían así el exterior constitutivo de aquella sexualidad regulada, de aquellos cuerpos interpelados eficazmente por los patrones dominantes. Pero estamos justamente en un momento histórico en el que esas sexualidades y esos cuerpos aun no habían sido encuadrados dentro de las pautas de la normalidad, en la época en que comienzan a circular los discursos que intentan catalogarlos, clasificarlos y encasillarlos, tratando de atrapar su diferencia en los muros que delimitan el campo de los "cuerpos que no importan", de los cuerpos excluidos. $Y$ justamente por ello este período resulta tan interesante, pues es el momento en que se está articulando tanto el discurso hegemónico sobre la sexualidad como su exterior constitutivo, compuesto por otros discursos que desbordan aquella articulación y la subvierten, como subvirtió el tango prostibulario la moral de la burguesía y el discurso normalizador de la medicina y la criminología.

Por ello, las prácticas desplegadas por estos cuerpos abyectos en el terreno del baile y las letrillas pueden ser interpretadas como tácticas microscópicas, huidizas, inquietas, improvisadas, semejantes a las que De Certeau (2000) postula como contrapartida del poder disciplinario, actos inorgánicos, dispersos, efímeros, propios de quienes resistían las formas socialmente impuestas del género y la sexualidad - 
envolviendo y fascinando en su mundo de encanto, movimiento y sexo-. Estas prácticas contribuyeron a crear, definir y amalgamar el tango y con él, la identidad de los oprimidos que, en sus distintas manifestaciones -putas, homosexuales, inmigrantes- articularon un discurso disruptivo que canalizó simbólicamente, en el tango, una forma de resistencia.

\section{Reflexiones finales}

Paulatinamente, el tango salió del prostíbulo y fue invadiendo la ciudad con su música. Reproducido a través de organitos y tarareado por la población, llegó a los oídos de jóvenes que al principio debían cantarlo y bailarlo en secreto, a escondidas de la mirada censora de sus mayores, para quienes el tango continuaba siendo sinónimo de inmoralidad. Poco después el tango se convierte en el "baile de las hermanas", como lo llama Tallón, deja de ser un baile impropio para las mujeres "decentes" y alcanza una popularidad extraordinaria. En este proceso el tango dejó de ser rechazado por las clases altas. Los historiadores y estudiosos del género suelen identificar un hecho clave en esta nueva aceptación: el triunfo del tango en París, con toda la connotación que esa ciudad faro poseía para la oligarquía local (Savigliano, 1995; Garramuño, 2007). En efecto, el tango conquistó los salones parisinos, causando revuelo al comienzo y entusiasmo después.

La danza que se impuso resultó distinta a la que se bailaba en el prostíbulo, pues ya había sido despojada de su costado libidinoso, de pasos sensuales, de cortes y quebradas. Al tiempo que el tango triunfaba, su baile sufrió una importante transformación que sustrajo de su escenificación parte de su carácter sexualizado y erótico. Así se dejó de bailar aquel provocador tango de lupanar: lo que se baila a partir de entonces en los salones es un tango "liso", al piso, recatado.

Los historiadores señalan que el tango triunfa, se expande y se populariza pero al precio de "adecentarse", perdiendo así su carácter revulsivo, pornográfico y picaresco. A partir de la década del '10 y con vigor desde la llamada "época de oro" del tango, los años '40, los tangos van diferenciándose de aquellos primeros temas prostibularios. Ya no se canta al sexo ni el tono de sus letras es alegre. Por el contrario, es posible percibir en su ritmo y en sus melodías un halo melancólico y más bien triste, un tono llorón -tan detestado por Borges-, para algunos expresión de una nostalgia hacia un paraíso perdido -el del lugar desde donde se emigró- que en realidad nunca se conoció, pues quienes protagonizan este período en el tango no son tanto los inmigrantes como sus hijos, nacidos y criados en estas tierras (Matamoro, 1969).

Este proceso de adecentamiento también afectó a las letras de tango. Los tópicos más recurrentes comienzan a centrarse, poco a poco, en el hombre abandonado, el bacán traicionado, el enfrentamiento barrio-puro vs. centro-perdición, el valor de la madre sacrificada y la novia decorosa frente a la mujer fácil, esa que elige una vida desvergonzada y siempre termina sus días fatídicamente, pagando en la vejez los excesos y la mala vida de la juventud. El tango se va moviendo por el espacio urbano y el espacio social para penetrar en los cabarets de las clases altas situados al norte de la ciudad y en las casas de familia, alejándose de las zonas marginales, en un proceso que 
modificó su territorio, sus letras y la forma de su danza, y conllevó, con el tiempo, una transformación en el sujeto interpelado por su discurso: ya no los marginales, esos seres que incomodaban con su sola presencia, sino un sujeto popular que fue integrado en una nueva articulación hegemónica (Vila, 2000).

Para entonces, la Argentina había logrado la integración del hijo del inmigrante y las políticas profilácticas desarrolladas en las décadas anteriores habían dado sus frutos: los seres más revoltosos fueron expulsados o bien mediante leyes que sancionaron la deportación de los comunistas y los anarquistas que atentaban contra el orden social, o bien mediante una estrategia de invisibilización, que hizo socialmente imperceptibles a quienes transgredían las normas morales vinculadas con el género y la sexualidad. Este proceso afectó al tango, que incorporó en su discurso la moralidad dominante, autoinculpándose por aquello mismo de lo que había sido acusado.

Por cierto, la madama y el compadrito no desaparecieron de las letras de tango, pero su presencia se volvió distante, como un eco lejano de un pasado superado, un momento fundacional y mítico que no tardó en exotizarse, como señala Savigliano (1995), convirtiendo su potencia transgresora en puro gesto, despojado de la fuerza subversiva que alguna vez tuvo. Aquellos cuerpos abyectos que fueron los protagonistas del primer tango y expresaron a través de su performance modalidades alternativas de la sexualidad, el género y la moral, se volvieron socialmente menos visibles una vez que la estrategia de normalización y sus correspondientes políticas del cuerpo lograron difundirse y hacerse hegemónicas. Esos cuerpos abyectos también fueron desapareciendo del tango, que si bien los retomó en algunos momentos, lo hizo a través del tamiz anestesiante del exotismo, apelando a figuras pintorescas y estereotipadas, tan hundidas en el pasado que se volvían inofensivas y hasta casi amistosas. De este modo, las aristas más transgresoras, los aspectos más perturbadores de los cuerpos abyectos se borraban ante la nueva claridad que acompañaba a los cuerpos que importan, los cuerpos de la normalidad que se imponía a partir de ese momento. Una nueva época sin duda se asentaba en una nueva corporalidad.

Tendrán que pasar muchos años para que estas aristas disruptivas regresen al tango. Un nuevo cambio de siglo, esta vez del $X X$ al $X X I$, va a inaugurar una nueva sensibilidad de la que el tango se hará nuevamente eco, abriendo, primero en el baile y luego en las letras, sus puertas a la exploración de las formas alternativas del género y la sexualidad con la emergencia del denominado tango queer y los versos de nuevas letristas mujeres. Pero es mucho tiempo el que habrá de esperarse y esa, ya es otra historia, un nuevo giro en este largo y sinuoso devenir.

\section{Bibliografía}

Bajtin, Mijail (1989): La cultura popular en la Edad Media y en el Renacimiento: El contexto de Francoise Rabelais. Madrid: Alianza Universidad.

Batiz, Adolfo (1908): Buenos Aires, la ribera y los prostíbulos en 1880: contribución a los 
Revista Punto Género N ․ํ 15 Junio de 2021

ISSN 0719-0417 / 137- 154

estudios sociales (libro rojo). Buenos Aires: Ediciones Aga-Taura

Botana, Natalio (1986). El orden conservador. Buenos Aires, Hyspamérica

Bunge, Carlos (1927): Estudios pedagógicos. Madrid: Espasa Calpe

Butler, Judith (2001): Géneros en disputa. El feminismo y la subversión de la identidad. Buenos Aires: Paidós

Butler, Judith (2005): Cuerpos que importan. Sobre los límites materiales y discursivos del cuerpo. Buenos Aires: Paidós

Caride Bartrons, Horacio (2009): “Apuntes para una geografía de la prostitución en Buenos Aires 1904-1936" en Seminario de Crítica, No. 162, Año 2009, Instituto de Arte Americano e Investigaciones estéticas, disponible en http://www.iaa.fadu.uba.ar/publicaciones/critica/0162.pdf, visitada el 5/11/2014

Collier, Simon (1997): "Ha nacido el tango entre las décadas de 1880 y 1920" en Collier et al ¡Tango!, Bacerlona: Paidós

Conde, Oscar (2004). Diccionario etimológico de lunfardo. Buenos Aires: Taurus.

De Certeau, Michel (2000): La invención de lo cotidiano. Vol. 1. Artes de Hacer. México DF: ITESO/Universidad Iberoamericana.

De Lara, Tomas \& Roncetti, Inés (1981 [1968]): El tema del tango en la literatura argentina. Buenos Aires: Ediciones Culturales Argentinas

Devoto, Fernando (2003): Historia de la inmigración en la Argentina. Buenos Aires: Sudamericana

Foucault, Michel (2000): Historia de la sexualidad.1. La voluntad de saber. México DF: Siglo XXI

Garramuño, Florencia (2007): Modernidades primitivas. Tango, samba y nación. Buenos Aires: Fondo de Cultura Económica

Guy, Donna (1994): El sexo peligroso. La prostitución legal en Buenos Aires 1975-1955. Buenos Aires: Sudamericana

Lamas, Hugo \& Binda, Enrique (2008): El tango en la sociedad porteña. 1880-1920. Unquillo: Abrazos.

Matamoro, Blas (1969): La ciudad del tango. Buenos Aires: Galerna. 
Revista Punto Género N ․ํ 15 Junio de 2021

ISSN 0719-0417 / 137- 154

Matamoro, Blas (1971): Historia del Tango. Buenos Aires: Centro Editor de América Latina.

Rapoport, Mario. (2000): Historia económica, política y social de la Argentina. Buenos Aires: Ediciones Macchi

Recchini de Lattes, Zulma (1971): "La población de Buenos Aires, componentes demográficos del crecimiento entre 1855 y 1960", Editorial del Instituto.

Rock, David (1992): El radicalismo argentino, 1890-1930. Buenos Aires: Amorrortu

Romero, Luis Alberto (1994): Breve historia contemporánea de la Argentina. Buenos Aires: Fondo de Cultura Económica

Rossi, Vicente. (2001 [1926]): Cosas de negros. Los orígenes del tango y otros aportes rioplatenses. Buenos Aires:Taurus

Salas, Horacio (1986): El tango. Buenos Aires: Planeta

Salessi, Jorge (1997): "Medics, Crooks, and Tango Queens: The National Appopriation of a Gay Tango". En: Fraser Delgado, Celeste y J. Muñoz. Everynight Life. Culture and Dance in Latino/a America. Durham: Duke University Press.

Salessi, Jorge (2000): Médicos maleantes y maricas. Higiene, criminología y homosexualidad en la construcción de la nación argentina. Buenos Aires: 1871-1914. Rosario: Beatriz Viterbo

Savigliano, Marta (1995): Tango and the Political Economy of Passion. Colorado: Westview Press

Soler Cañas, Luis (1965): Los orígenes de la literatura lunfarda. Buenos Aires: Ediciones Siglo XX

Tallón, José Sebastián (1964 [1959]): El tango en sus etapas de música prohibida. Buenos Aires, Cuadernos del Instituto Amigos del Libro Argentino

Varela, Gustavo (2005): Mal de tango. Historia y genealogía moral de la música ciudadana. Buenos Aires: Paidós

Vega, Carlos (2007): Estudio para los orígenes del tango argentino. Buenos Aires: Editorial de la Universidad Católica.

Vila, Pablo (2000): “El tango y las identidades étnicas en Argentina”. En Pelinski, Ramón. (comp): El tango nómade. Ensayos sobre la diáspora del tango. Buenos Aires: 
Revista Punto Género N ․ํ 15 Junio de 2021

ISSN 0719-0417 / 137- 154

El Corregidor, p. 71-97.

\section{Fuentes consultadas}

1889 Censo General de Población, Edificación, Comercio e Industria de la ciudad de Buenos Aires de 1887. Buenos Aires: Compañía Sudamericana de Billetes de Banco. Vol 1 y 2.

1872 Primer Censo de la República Argentina. Buenos Aires: Imprenta El Porvenir. 